\title{
Treatment of advanced neuroendocrine tumours with radiolabelled somatostatin analogues
}

\author{
G A Kaltsas ${ }^{1,2}$, D Papadogias ${ }^{1,3}$, P Makras ${ }^{3}$ and A B Grossman ${ }^{1}$
}

\author{
${ }^{1}$ Department of Endocrinology, St Bartholomew's Hospital, London EC1A 7BE, UK \\ ${ }^{2}$ Department of Pathophysiology, University of Athens, Athens, Greece \\ ${ }^{3}$ Department of Endocrinology, G Gennimatas General Hospital, Athens, Greece \\ (Requests for offprints should be addressed to A B Grossman; Email: a.b.grossman@qmul.ac.uk)
}

\begin{abstract}
Neuroendocrine tumours (NETs) constitute a heterogeneous group of tumours that frequently express cell membrane-specific peptide receptors, such as somatostatin receptors (SSTRs), and of which gastroenteropancreatic (GEP), carcinoid and pancreatic islet cell tumours exhibit the highest expression of SSTRs. Radiolabelled receptor-binding somatostatin analogues (octreotide and lanreotide) act as vehicles to guide radioactivity to tissues expressing SSTRs, and can thus be used for their diagnosis and treatment. After the localization of NETs bearing SSTRs with ${ }^{111}$ In-octreotide (OctreoScan), a number of radioisotopes with different physical properties have been used for their treatment. The administration of high doses of the Auger electron and $\gamma$-emitter ${ }^{111}$ In-diethylenetriaminepenta-acetic acid (DTPA) ${ }^{0}$,octreotide in patients with metastatic tumours has been associated with considerable symptomatic improvement but relatively few and short-lived objective tumour responses. The use of another radiolabelled somatostatin analogue coupled with ${ }^{90} \mathrm{Y}$, a pure $\beta$-emitter, ${ }^{90} \mathrm{Y}-1,4,7,10$-tetraazacyclododecane- $N, N^{\prime}, N^{\prime \prime}, N^{\prime \prime \prime}$-tetraacetic acid (DOTA $)^{0}$, Tyr $^{3}$,octreotide $\left({ }^{90} \mathrm{Y}\right.$-DOTATOC, OctreoTher), was associated with $10-30 \%$ objective tumour response rates, and appears to be particularly effective in larger tumours. ${ }^{111}$ In- and ${ }^{90} \mathrm{Y}$-DOTA-lanreotide has also been used for the treatment of NETs although its therapeutic efficacy is probably inferior to that of octreotide-based radiopharmaceuticals. More recently, treatment with ${ }^{177}$ Lu-DOTA ${ }^{0}$, Tyr ${ }^{3}$ octreotate ( ${ }^{177}$ Lu-DOTATATE), which has a higher affinity for the SSTR subtype 2 , resulted in approximately $30 \%$ complete or partial tumour responses; this radiopharmaceutical is particularly effective in smaller tumours. Furthermore, treatment using both ${ }^{90} \mathrm{Y}$-DOTATOC and ${ }^{177} \mathrm{Lu}_{\text {-DOTA }}{ }^{0}, \mathrm{Tyr}^{3}$ octreotate seems promising, as the combination of these radiopharmaceuticals could be effective in tumours bearing both small and large lesions. Tumour regression is positively correlated with a high level of uptake on ${ }^{111}$ In-octreotide scintigraphy, limited tumour mass and good performance status. In general, better responses have been obtained in GEP tumours than other NETs. The side effects of this form of therapy are relatively few and mild, particularly when kidney-protective agents are used. Treatment with radiolabelled somatostatin analogues presents a promising tool for the management of patients with inoperable or disseminated NETs, and particularly GEP tumours.
\end{abstract}

Endocrine-Related Cancer (2005) 12 683-699

\section{Introduction}

Neuroendocrine tumours (NETs) constitute a heterogeneous group of tumours that originate from the diffuse endocrine system (DES). This system includes endocrine glands, such as the pituitary, the parathyroids and the adrenal medulla, as well as endocrine islets within glandular tissue (thyroid or pancreatic) and cells disseminated between exocrine cells, such as endocrine cells of the digestive and respiratory tracts (Arnold et al. 1994, Kaltsas et al. 2004a). The latter are usually known as 'carcinoid tumours', and, according to their anatomic site of origin, they have been classified as foregut, midgut and 
hindgut carcinoid tumours (Solcia et al. 1999). Within these subgroups, the biological behaviour of the tumours can vary significantly (Oberg 2004a, Oberg et al. 2004). NETs occur either sporadically or as part of familial syndromes, and although some may show aggressive behaviour and become highly malignant (poorly differentiated NETs), the great majority are either benign or relatively slow growing (welldifferentiated NETs), retaining many multipotent differentiation features (Kaltsas et al. 2001a). Such features include the possession of neuroamine uptake mechanisms and/or specific receptors at the cell membrane, such as somatostatin receptors (SSTRs), which can be used for the identification, localization and therapy of NETs (Oberg 2002, 2004a). Of the five major subtypes of SSTR, SSTR ${ }_{1-5}, \mathrm{SSTR}_{2}$ and SSTR are the ones most commonly expressed in NETs; however, there is considerable variation in SSTR subtype expression among the different tumour types and among tumours of the same type (de Herder et al. 2003).

Radiopharmaceuticals are radiolabelled substances that can be utilized for the identification and localization of NETs by their ability to bind to suitable ligands (Kaltsas et al. 2001b). They form an imaging modality which is based on the physiological (the presence of functioning receptors) rather than the anatomical characteristics of the tumours (de Herder et al. 1996). As the majority of NETs express SSTRs they form an ideal target for treatment with somatostatin analogue (SST analogue)-derived radiopeptides (Krenning et al. 1999a, de Herder et al. 2003). SST analogues are synthetic peptides (octreotide, Novartis, Basel, Switzerland, and lanreotide, Ipsen, Paris, France) that exert most of the biological actions of the native peptide somatostatin, but have a longer half-life ( $2 \mathrm{~min}$ vs $\sim 90 \mathrm{~min}$ ), being resistant to plasma degradation (de Herder et al. 2003). The high affinity of these peptides for SSTRs (highest affinity for $\mathrm{SSTR}_{2}$, moderately high for $\mathrm{SSTR}_{5}$ and intermediate for $\mathrm{SSTR}_{3}$ ) and the internalization of the receptor-peptide complex facilitate retention of the radiopeptide in receptorexpressing tumours, whereas their relatively small size facilitates rapid clearance from the blood (Reubi et al. 2004). In order to ensure the stability of the molecule, the peptide labelled with a radioisotope is bound to a chelator. Covalently linking ethylene-triamine-pentaacetic acid (DTPA) with octreotide results in DTPAoctreotide (pentetreotide); this tracer was initially labelled with ${ }^{123} \mathrm{I}$, but it gradually became evident that it is more clinically effective in localizing NETs when labelled with ${ }^{111}$ In (Kaltsas et al. 2004a) (Fig. 1). Subsequently, labelled lanreotide was also introduced,
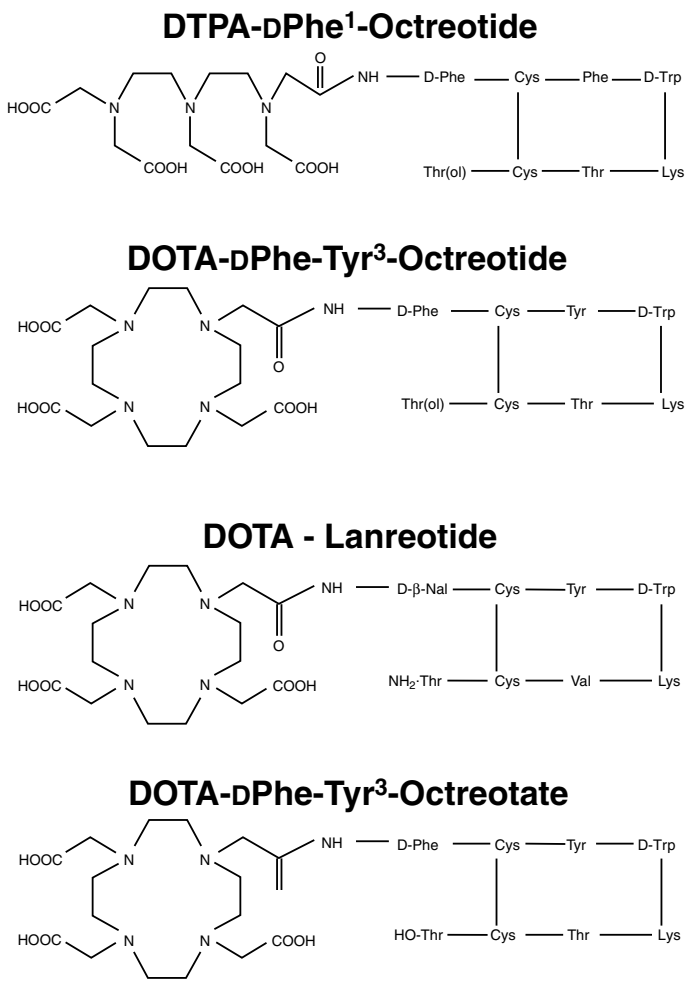

Figure 1 Currently used ligands for treatment with radiopeptides based on somatostatin analogues.

but the images obtained with this radionuclide were generally inferior to those of octreotide (Virgolini et al. 2002a,b).

The injected activity of ${ }^{111}$ In-pentetreotide is about $200 \mathrm{MBq}$ (containing at least $10 \mu \mathrm{g}$ of the peptide); approximately $80 \%$ of the i.v. administered ${ }^{111}$ In-pentetreotide is eliminated via the urinary system (Krenning et al. 1999b). Due to its relatively long halflife, planar and single photon emission computerized tomography (SPECT) images can be acquired at 24 and $48 \mathrm{~h}$ when interfering background radioactivity is minimized by renal clearance. Normal scintigraphic features include visualization of the thyroid, spleen, liver, pituitary, urinary bladder and occasionally the bowel (Krenning et al. 1999b, de Herder et al. 2003). Scintigraphy with ${ }^{111}$ In-octreotide represents the imaging modality of choice in the initial evaluation of gastroenteropancreatic (GEP) and islet cell tumours, exhibiting a sensitivity of $67-100 \%$; it can identify clinically unsuspected lesions and optimize the overall staging of these tumours (Kaltsas et al. 2001a,b). Chromaffin cell tumours (phaeochromocytomas and paragangliomas) also express SSTRs, and scintigraphy with ${ }^{111}$ In-octreotide can be used 
Table 1 Physical properties of $\beta$-emitting isotopes used for targeted radiotherapy

\begin{tabular}{|c|c|c|c|c|c|}
\hline Radioisotope & $\begin{array}{c}\text { Maximum energy } \\
\text { gamma } \\
\text { emission (keV) }\end{array}$ & $\begin{array}{c}\text { Physical } \\
\text { half-life } \\
\text { ( } T_{1 / 2} \text { days) }\end{array}$ & $\begin{array}{l}\text { Maximum particle } \\
\text { range }(\mathrm{mm})\end{array}$ & $\begin{array}{c}\text { Mean particle } \\
\text { range }(\mathrm{mm})\end{array}$ & $\begin{array}{c}\text { Beta } \\
\text { emission } \times 90 \\
(\mathrm{~mm} \text { in water })\end{array}$ \\
\hline${ }^{153} \mathrm{Sm}$ & 103 & 1.93 & & & 1.01 \\
\hline${ }^{90} \mathrm{Y}$ & 2284 & 2.67 & 12 & 4.2 & 5.34 \\
\hline${ }^{186} \mathrm{Re}$ & 1037 & 3.78 & & & 1.8 \\
\hline${ }^{177} \mathrm{Lu}$ & 497 & 6.68 & 1 & 0.27 & - \\
\hline${ }^{131} \mid$ & 606 & 8.04 & 2.4 & 0.45 & 0.83 \\
\hline${ }^{32} \mathrm{P}$ & - & 14.28 & 8.7 & & 3.61 \\
\hline${ }^{89} \mathrm{Sr}$ & - & 50.52 & & & \\
\hline
\end{tabular}

Adapted from Wiseman and Kvols 1995 and Lewington 2003.

particularly in cases of ${ }^{123}$ I-metaiodobenzylguanidine (MIBG)-negative lesions, whereas in cases of medullary thyroid carcinoma (MTC), scintigraphy with ${ }^{111}$ In-octreotide has a sensitivity of $50-75 \%$ (Kaltsas et al. 2001b). Parathyroid and pituitary tumours also express SSTRs and can be imaged with ${ }^{111}$ In-octreotide; however, this is not the imaging modality of choice for these tumours (Krenning et al. 2005).

After the introduction of radiolabelled octreotide for the diagnosis of lesions expressing SSTRs, the next step was to use this radiopharmaceutical to develop specific therapy, particularly for inoperable or multiple-site tumours showing diagnostic uptake of ${ }^{111}$ In-octreotide (Lewington 2003). As SSTRs are mainly expressed in GEP tumours, these tumours represent the main target group for therapy with radiolabelled peptides (de Herder et al. 2003).

\section{Basic concepts of applying therapy with radiopharmaceuticals to NETs}

The initial management of NETs is surgical excision of the primary tumour, unless specific medical therapy is available. This form of treatment usually suffices for the majority of benign tumours, but recurrent, malignant and disseminated tumours require further treatment; this is particularly relevant to the majority of GEP tumours (Oberg et al. 2004). SST analogues and interferon-alpha (IFN- $\alpha$ ) can achieve disease stabilization but, eventually, further treatment will be required for primary and metastatic tumours that continue to grow; this has traditionally been in the form of systemic chemotherapy and external radiotherapy for local control (Kaltsas et al. 2004b, Oberg et al. 2004). Although systemic chemotherapy can be temporarily effective in the minority of patients with poorly differentiated NETs, the majority of well-differentiated NETs are relatively chemoresistant (Kaltsas et al. 2004b, Oberg et al. 2004). Chemotherapy itself is also associated with considerable side effects, and thus its use must be weighed against potential adverse effects (Kaltsas et al. 2004b). Different forms of treatment with a more favourable side-effect profile are highly required for patients with well-differentiated metastatic NETs, particularly as such patients can experience prolonged survival in the presence of extensive disease (Oberg 2004b, Oberg et al. 2004).

The application of therapy with radiopharmaceuticals to NETs is dependent on the concept that coupling a radioisotope to a molecule which would specifically bind to tumour cells could deliver an effective radiation dose to the tumour without damaging healthy tissues, thus limiting adverse effects (Krenning et al. 1999a). The success of this approach depends upon the amount of radioligand that can be concentrated within tumour cells and the rates of internalization, degradation and recycling of both ligand and receptor (Wiseman \& Kvols 1995). The radioisotope's physical properties are important for targeting radiation therapy because even though tumour heterogeneity can cause incomplete responses, crossfire from the radioisotope localized on target-positive tumour cells can kill the nearby tumour cells that are target negative (Krenning et al. 2004, Kwekkeboom et al. 2005, Pauwels et al. 2005, Reubi 2005). The radioisotope selection is based on the type of radiation emitted, the emission energies, the distance over which the energy is deposited, and the physical half-life of the radioisotope (Tables 1 and 2). According to this concept, $\beta$-, $\alpha$ - or Auger electron emitters can deliver a cytotoxic dose of radiation with a high linear energy transfer selectively to tumours expressing SSTRs; the $\beta$-emitter selected must have an appropriate path to reach the cell nucleus (probably the principal, although not the sole, target to achieve cell death) 
Table 2 Physical properties of currently used radioisotopes for targeted radiotherapy of neuroendocrine (gastroenteropancreatic, GEP) tumours in relation to ${ }^{131} \mathrm{I}$, the most widely used radioisotope for the treatment of differentiated thyroid carcinoma

\begin{tabular}{|c|c|c|c|c|c|c|}
\hline \multirow[b]{2}{*}{ Radioisotope } & \multirow{2}{*}{$\begin{array}{c}\text { Half-life } \\
\text { (T/2) (days) }\end{array}$} & \multirow{2}{*}{$\begin{array}{l}\text { Maximum energy } \\
(\mathrm{keV})\end{array}$} & \multirow{2}{*}{$\begin{array}{l}\text { Maximum range } \\
(\mathrm{mm})\end{array}$} & \multirow{2}{*}{$\begin{array}{c}\text { Sphere } \\
\text { diameter }(\mathrm{mm})\end{array}$} & \multicolumn{2}{|c|}{$\begin{array}{c}\text { \% Energy absorption } \\
\left({ }^{90} \mathrm{Y} /{ }^{177} \mathrm{Lu}\right)^{*}\end{array}$} \\
\hline & & & & & ${ }^{90} Y$ & ${ }^{177} \mathrm{Lu}$ \\
\hline${ }^{131} \mid$ & 8 & 606 & 2.4 & 50 & 95 & 100 \\
\hline${ }^{90} \mathrm{Y}$ & 2.7 & 2284 & 12 & 30 & 91 & 99.6 \\
\hline \multirow[t]{5}{*}{${ }^{177} \mathrm{Lu}$} & 6.7 & 497 & 1 & 10 & 66 & 97 \\
\hline & & & & 5 & 41 & 93 \\
\hline & & & & 3 & 26 & 88 \\
\hline & & & & 1 & 9 & 67 \\
\hline & & & & 0.1 & 1 & 15 \\
\hline${ }^{111}$ In & 2.8 & 245 (IC) & $550 \mu \mathrm{m}$ & & & \\
\hline & & $25(\mathrm{Au})$ & $10 \mu \mathrm{m}$ & & & \\
\hline
\end{tabular}

${ }^{*}$ High-energy $\beta$-particles are not efficient in small metastases, since only a small fraction of the energy will be deposited in such small targets. IC: Internal conversion. Au, Auger electrons.

Adapted from Kassis \& Adelstein 2005 and Siegel JA \& Stabin MG 1994.

depending upon the site of cellular radiopharmaceutical concentration (Siegel \& Stabin 1994, Lewington 2003). Physical half-life directly relates to the rate at which the absorbed radiation dose is delivered; a higher dose rate is best suited to rapidly dividing tumours, whereas a longer physical half-life may be more effective for relatively slow-growing tumours such as the majority of NETs (Lewington 2003, Pauwels et al. 2005).

To date, the best paradigm for a radiopharmaceutical targeting agent is that for radioiodine $\left({ }^{131} \mathrm{I}\right)$ used for the treatment of thyroid disorders; this agent's favourable physical characteristic include a high target-to-nontarget ratio, rapid clearance of the unbound radioisotope and a long residence time in the target tissue (Wiseman \& Kvols 1995). Information derived from patients with differentiated thyroid carcinoma treated with ${ }^{131} \mathrm{I}$ has proven its therapeutic efficiency and the absence of major side effects (Robbins \& Schlumberger 2005) (Table 2). Information on the biodistribution of ${ }^{111}$ In-DTPA-D-Phe ${ }^{1}$-octreotide after i.v. injection, including activity concentrations and absorbed doses in tumour and normal tissues, in patients with various tumour types demonstrated that carcinoid tumours exhibit the highest ${ }^{111}$ In activity concentration in tumour tissue and tumour-to-blood ratio, therefore making these tumours an ideal target (Forssell-Aronsson et al. 2004). In addition, radiopeptide uptake in metastases was higher than in primary tumours; this was attributed to the differential expression of SSTR subtypes and differences in total expression of SSTRs between primary and secondary tumours (de Jong et al. 2003). A major advantage of treatment with radiopharmaceuticals is that radiation can be delivered selectively not only to large primary tumours and metastases but also to subclinical tumours and metastases that are too small to be imaged and identified for surgery or external beam radiotherapy (de Jong et al. 2003). Due to high individual variation between patients, when radiolabelled octreotide is to be used for therapy it is advisable to perform individual dosimetric calculations (Forssell-Aronsson et al. 2004).

Targeted radiotherapy for NETs (mainly GEP tumours) is mostly performed with radiopeptides based on SST analogues; the ligands that are currently in clinical use are shown in Fig. 1 (DTPA octreotide, DOTA- ${ }_{D}$ Phe-tyr ${ }^{3}$-octreotide (DOTA TOC), DOTA${ }_{D}$ Phe-Tyr ${ }^{3}$-octreotate (DOTATATE) and DOTAlanreotide) (Krenning et al. 2005, Reubi et al. 2005). ${ }^{111}$ In-DTPA exhibits moderate binding affinity for $\mathrm{SST}_{2}$ (negligible for $\mathrm{SST}_{1,3-5}$ ), while ${ }^{111} \mathrm{In}$ is mainly an Auger electron emitter exhibiting only short-range radiotoxicity. However, DTPA is not an ideal chelator for the currently used $\beta$-particle emitters such as yttrium-90 $\left({ }^{90} \mathrm{Y}\right)$ and lutetium-177 $\left({ }^{177} \mathrm{Lu}\right)$; for these radioisotopes, the macrocyclic chelator 1,4,7,10-tetraazacyclododecane- $N, N^{\prime}, N^{\prime \prime}, N^{\prime \prime \prime}$-tetraacetic acid (DOTA) is better, as it forms stable complexes with the isotopes. The DOTA-coupled, somatostatin-based radiopharmaceuticals are ${ }^{90} \mathrm{Y}$-DOTA ${ }^{0}-\mathrm{Tyr}^{3}$-octreotide $\left({ }^{90} \mathrm{Y}\right.$-DOTATOC), ${ }^{90} \mathrm{Y}$-DOTA-lanreotide and ${ }^{177}$ Lu-DOTA-Tyr ${ }^{3}$-Thre ${ }^{8}$-octreotide $\quad\left({ }^{177}\right.$ Lu-DOTATATE), shown in Fig. 2. These differ with regard to SST receptor affinity profile (Table 3 ), the DOTATATE derivative exhibiting the highest affinity to $\mathrm{SSTR}_{2}$ and DOTA-lanreotide having the lowest affinity to $\mathrm{SSTR}_{2}$ although demonstrating considerable $\mathrm{SSTR}_{5}$ affinity (Krenning et al. 2005). The various factors that may determine the amount of uptake of 


\section{\begin{tabular}{ccc} 
Radioisotope & Che lator & Peptide moiety \\
\hline 111 In $90 Y 177$ &
\end{tabular} \\ ${ }^{111} \mathrm{In},{ }^{90} \mathrm{Y},{ }^{177} \mathrm{Lu}$ DTPA or DOTA octreotide analogue}
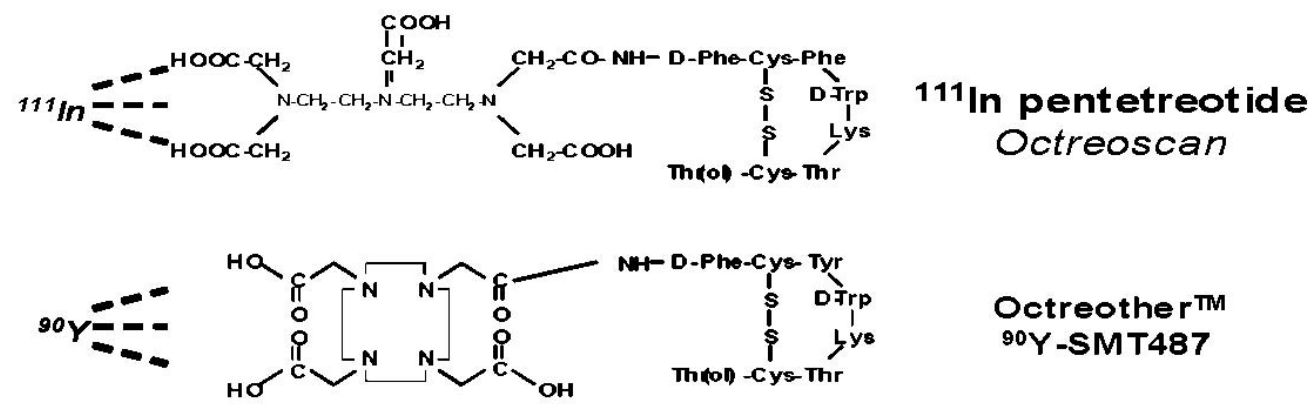

\section{Octreothe $\mathrm{r}^{\mathrm{TM}}$ \\ $90 Y-S M T 487$}
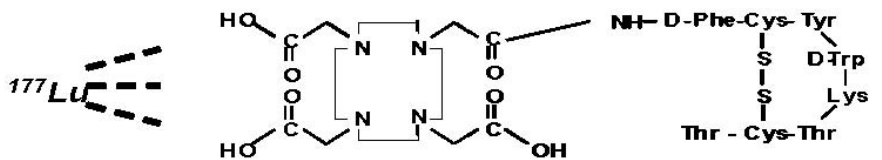

\section{Lu-DO TA-octreotate}

Figure 2 Chemical structure of currently used octreotide-based radiopharmaceuticals for the treatment of gastroenteropancreatic and other neuroendocrine tumours (Octreother $\left.{ }^{\mathrm{TM}}={ }^{90} \mathrm{Y}-\mathrm{SMT} 487={ }^{90} \mathrm{Y}-\mathrm{DOTATOC}\right)$.

radiolabelled SST analogues have been recently outlined as follows:

1. the stability of the radioligand

2. the density of SSTR expression on the tumour

3. the type of SSTRs expressed by the tumour

4. the affinity of the radioligand for the SSTRs

5. the efficiency of SSTR-mediated internalization and recycling

6. the final trapping of the radioisotopes within the tumour cells

7. the mass of the injected peptide (de Herder et al. 2003).

\section{Dosimetry}

Radiopharmaceuticals are taken up by both tumour cells and normal tissues, and this form of therapy aims to deliver the highest possible dose to the tumour while sparing normal tissues from damage (Pauwels et al.
2005). As in other forms of treatment aiming at the elimination of neoplastic cells, critical dose-limiting organs in therapy with radiopharmaceuticals are the bone marrow and the kidneys, the latter due to interstitial irradiation derived from tubular peptide reabsorption (Bodei et al. 2004a). This was evident from preliminary clinical trials using ${ }^{111}$ In- and ${ }^{90}$ Y-labelled peptides in which the considerable therapeutic benefits noted in patients with progressive disease were associated with significant, mostly delayed toxicity leading to substantial morbidity (Otte et al. 2002, Valkema et al. 2002). Dosimetry methods can be used to provide reliable dose estimates to critical organs and to tumoral tissues before therapy, leading to individualized therapeutic regimes; dosimetry can help to identify patients who would benefit from therapy with radiopharmaceuticals while excluding unsuitable patients (Bodei et al. 2004a, Pauwels et al. 2005). These estimations require time-consuming and sophisticated methods, including pharmacokinetic,

Table 3 Affinity profiles for somatostatin receptors of currently used octreotide-based radiopharmaceuticals (SSTR $\left.{ }_{1-5}\right)$

\begin{tabular}{lccccc}
\hline Radiopharmaceutical & SSTR $_{\mathbf{1}}$ & SSTR $_{\mathbf{2}}$ & SSTR $_{\mathbf{3}}$ & SSTR $_{\mathbf{4}}$ & SSTR $_{\mathbf{5}}$ \\
\hline Native somatostatin SS-28 & 5.2 & 2.7 & 7.7 & 5.6 & 4.0 \\
${ }^{111}$ In-DTPA-octreotide & $>10000$ & 22 & 182 & $>1000$ & 237 \\
${ }^{90}{ }^{\text {Y-DOTA-Tyr }}{ }^{3}$ octreotide & $>10000$ & 20 & 27 & $>10000$ & 57 \\
${ }^{177}$ Lu-DOTA, Tyr $^{3}$ octreotate & 10000 & 15 & $>1000$ & 453 & 547 \\
\hline
\end{tabular}

DTPA: diethylenetriaminepentaacetic acid; DOTA: 1,4,7,10-tetraazacyclododecane- $N, N^{\prime}, N^{\prime \prime}, N^{\prime \prime \prime}$-tetraacetic acid.

Adapted from Reubi et al. 2000. 
biodistribution and wash-out studies involving the selected radiopharmaceutical to be used for therapy (Kassis \& Adelstein 2005, Pauwels et al. 2005).

\section{Selection of the radiopharmaceutical}

The chemical structure of the radiopharmaceutical is important, as it influences tumour uptake, renal clearance and retention, and residence time in tissues (Reubi et al. 2000). Dosimetry with ${ }^{111}$ In-octreotide can easily be performed when this same radiopharmaceutical is to be used for treatment (Cremonesi et al. 1999, Pauwels et al. 2005). However, this is not possible with ${ }^{90} \mathrm{Y}$-radiopharmaceuticals, as the $\beta$-emission of ${ }^{90} \mathrm{Y}$ does not allow appropriate quantification from the $\gamma$-activity emitted by affected cells, necessitating the use of alternative approaches. Imaging with the peptide surrogate labelled with the positron emitter ${ }^{86} \mathrm{Y}$ was precise in measuring distribution and retention of the radiopharmaceutical over time, but a major drawback is the requirement of a positron emission tomography (PET) facility and a high-energy cyclotron (Pauwels et al. 2005). A different method to overcome the limitations of using ${ }^{86} \mathrm{Y}$ was based on the evaluation of the biodistribution and dosimetry of DOTATOC radiolabelled with ${ }^{111}$ In (Cremonesi et al. 1999); however, biodistribution studies using ${ }^{111}$ In-DTPA octreotide have demonstrated either under- or overestimation of renal doses of ${ }^{90}$ Y-DOTATOC (Pauwels et al. 2005). Additional improvements in the determination of the kidney radiation dose can be obtained with the precise organ volume measurement (instead of a fixed volume) by computerized tomography (CT) or magnetic resonance imaging (MRI) (Barone et al. 2005). Patient-specific dosimetry requires quantitative imaging of the patient at different times points (according to the half-life of the radioisotope used) to evaluate the retention of activity in various organs over time. After integration of the measured activities, time integrals of activity are multiplied by energy-transport factors to obtain radiation dose estimates in target organs. Once these activities are measured, absorbed doses in target organs are calculated with dedicated software (Sgouros 2005). In cases where the absorbed dose is mainly related to self-irradiation, the energy transported per decay from the source tissue to the mass of the target tissue ( $\mathrm{S}$ factor) depends on the target volume; improvements in the accuracy of measured doses may thus be achieved by organ volume estimation using CT or MR imaging (Pauwels et al. 2005, Sgouros 2005).
Although it is clear that accurate prediction of absorbed doses is required for internal radiotherapy, inaccuracies can occur even with the use of highly sophisticated techniques, leading to miscalculation of the absorbed doses: this will lead to either under- or overtreatment with unpredictable toxicity (Pauwels et al. 2005).

\section{Evaluation of response}

Patients' responses to therapy should be evaluated by uniform criteria and divided into symptomatic, hormonal and tumour responses (Kaltsas et al. 2004a). Tumour responses are classified by WHO criteria as follows:

1. complete response, complete regression of all clinical and hormonal evidence of tumour, including radiological abnormalities

2. partial response, a $50 \%$ or greater reduction of all measurable tumour and no appearance of new lesions, along with hormonal and symptomatic improvement

3. stable disease, a less than $50 \%$ reduction or no greater than $25 \%$ increase of tumour size, hormonal measurements and symptoms

4. progression, appearance of new lesions or an increase of $25 \%$ or more of tumour size, and hormonal and symptomatic deterioration.

Patients are reviewed at 3-6-month intervals; review assessment comprises clinical, biochemical and radiological evaluation. The rationale of applying further treatment at these time intervals is contingent on the relatively prolonged replication period of these tumours (Kaltsas et al. 2004b).

\section{Pretreatment considerations}

A large number of NETs, mainly GEP tumours (functioning or non-functioning), are being treated with SST analogues; this is particularly important, as many of these tumours are associated with severe humoral syndromes (functioning tumours) for the control of which treatment with SST analogues is continuously required (Kaltsas et al. 2004b, Oberg 2004b). During treatment with these drugs, the uptake of ${ }^{111}$ In-DTPA-octreotide in SST-positive tumours and the spleen is diminished (similar to blocking the receptor binding of a labelled 'hot' peptide with an excessive amount of unlabelled 'cold' peptide). In practice, NETs may still remain visible during treatment with octreotide, although tumour uptake of ${ }^{111}$ In-octreotide may be substantially reduced. In order 
to maximize the uptake of radiolabelled compounds, patients on long-acting releasable (LAR) SST analogues should receive treatment with radiopharmaceuticals before the next LAR administration (4-6 weeks), or after they have been switched to s.c. octreotide, which has a much shorter half-life and can be discontinued $24 \mathrm{~h}$ before therapy (Kwekkeboom et al. 2005). Particular attention should be paid to patients with extensive hepatic involvement and high uptake on the diagnostic OctreoScan (Mallinckrodt Pelten, The Netherlands). These patients are at high risk of developing fulminant hepatic necrosis, as extremely high radiation may be delivered to the small number of normal liver cells from the increased uptake of the neighbouring metastatic foci (Kwekkeboom et al. 2005). In such cases, lowering the cycle dose is an alternative if treatment with radiopharmaceuticals is required (see below). In addition, when there is increased uptake in the bone marrow in patients with disseminated disease, it is important to exclude metastatic infiltration of the bone marrow, as treatment with radiopharmaceuticals may exacerbate the bone marrow failure after therapeutic radiation (Mukherjee et al. 2001). This is also important for patients who have previously undergone intensive chemotherapy (Bodei et al. 2004b).

\section{Peptide receptor radionuclide therapy with ${ }^{111}$ In-octreotide}

${ }^{111}$ In emits mainly $\gamma$-radiation, which passes through tissue relatively easily and can be imaged by a $\gamma$-scanner. ${ }^{111}$ In also emits Auger and conversion electrons that exert an anti-proliferative effect in malignant tumours if their major target, the DNA of the cell, is within the particle range (de Jong et al. 2002). In a study by Krenning et al. (1999b), 30 end-stage patients with NETs, including 20 patients with GEP tumours, were treated with [ ${ }^{111}$ In-DTPA]-octreotide, receiving a cumulative dose of $20 \mathrm{GBq}(550 \mathrm{mCi})$. Seven patients who were treated with a total dose of less than $20 \mathrm{GBq}$ ${ }^{111}$ In-DTPA-octreotide had to stop therapy prematurely due to the extension of their disease despite treatment. Of the 21 patients who received adequate doses of ${ }^{111}$ In-DTPA-octreotide (all had progressive disease), six demonstrated partial shrinkage of the tumour, while eight others showed stabilization of their disease; patients with higher tumour uptake tended to show better results (Krenning et al. 1999b). Similar results were obtained in a study that included 40 patients who received cumulative doses of $20-160 \mathrm{GBq}$. Therapeutic effects were seen in 21 patients: partial remission in one, minor remissions in six and stabilization of previously progressive tumours in 14 (Valkema et al. 2002). Nevertheless, three of the six patients who received more than $100 \mathrm{GBq}(2.7 \mathrm{Ci})$ developed a myelodysplastic syndrome or leukaemia, and the authors concluded that $100 \mathrm{GBq}$ are the maximal tolerable dose. In another study, 27 patients were treated with two doses of $6.5 \mathrm{GBq}$ $(180 \mathrm{mCi}){ }^{111}$ In-pentetreotide: objective partial responses occurred in two $(8 \%)$ patients and significant tumour necrosis in seven (27\%) (Anthony et al. 2002). Symptomatic and hormonal response was obtained in $62 \%$ and $81 \%$ respectively, whereas median survival was 18 months compared with the 6 months expected, without any major side effects (Anthony et al. 2002). However, a more recent study has challenged the long-term efficacy of ${ }^{111}$ In-pentetreotide therapy in patients with disseminated NETs (Buscombe et al. 2003). This is not surprising, as ${ }^{111}$ In-coupled peptides are not ideal for therapy with radiopharmaceuticals because of the small particle range and therefore lower tissue penetration rate; short-lived responses have been attributed to the preferential survival of resistant clones (de Jong et al. 1997, 2003, Kwekkeboom et al. 2005). Moreover, its efficacy in large tumours and end-stage patients is limited, reflecting mainly heterogeneous radiopharmaceutical uptake due to poor tumour vascularity and central necrosis (Lewington 2003). It has been therefore been suggested that ${ }^{111}$ In-octreotide should be given only with high-energy $\beta$-particle emitters in order to eradicate micrometastasis (de Jong et al. 2002), particularly as various studies with $\beta$-emitters alone have demonstrated better response rates (Valkema et al. 2002, de Jong et al. 2005, Kwekkeboom et al. 2005) (see below).

\section{Peptide receptor radionuclide therapy with $\left({ }^{90} \mathrm{Y}\right.$-DOTA $\left.{ }^{0} \mathrm{Tyr}^{3}\right)$-octreotide $\left[{ }^{90} \mathrm{Y}\right.$ - DOTATOC]}

Radiopeptides emitting $\beta$-radiation have superior therapeutic potential since the particles they emit have sufficient energy to cause cell damage without penetrating very far into surrounding tissue (Wiseman $\&$ Kvols 1995). A high-energy $\beta$-emitter attached to a SST analogue could potentially deliver a lethal dose of radiation to a SST-positive tumour with minimal damage to healthy tissue (Wiseman \& Kvols 1995, de Jong et al. 2003). Despite its diagnostic use, DTPAoctreotide is not suitable for labelling with yttrium-90 $\left({ }^{90} \mathrm{Y}\right)$, a pure energetic $\beta$-emitter well suited for internal radiotherapy; this has led to the development of a new peptide chelator that can be stably labelled with ${ }^{111}$ In and ${ }^{90} \mathrm{Y}$ (de Jong et al. 1997, Krenning et al. 1999a). The same SST analogue (Tyr ${ }^{3}$-octreotide) used 


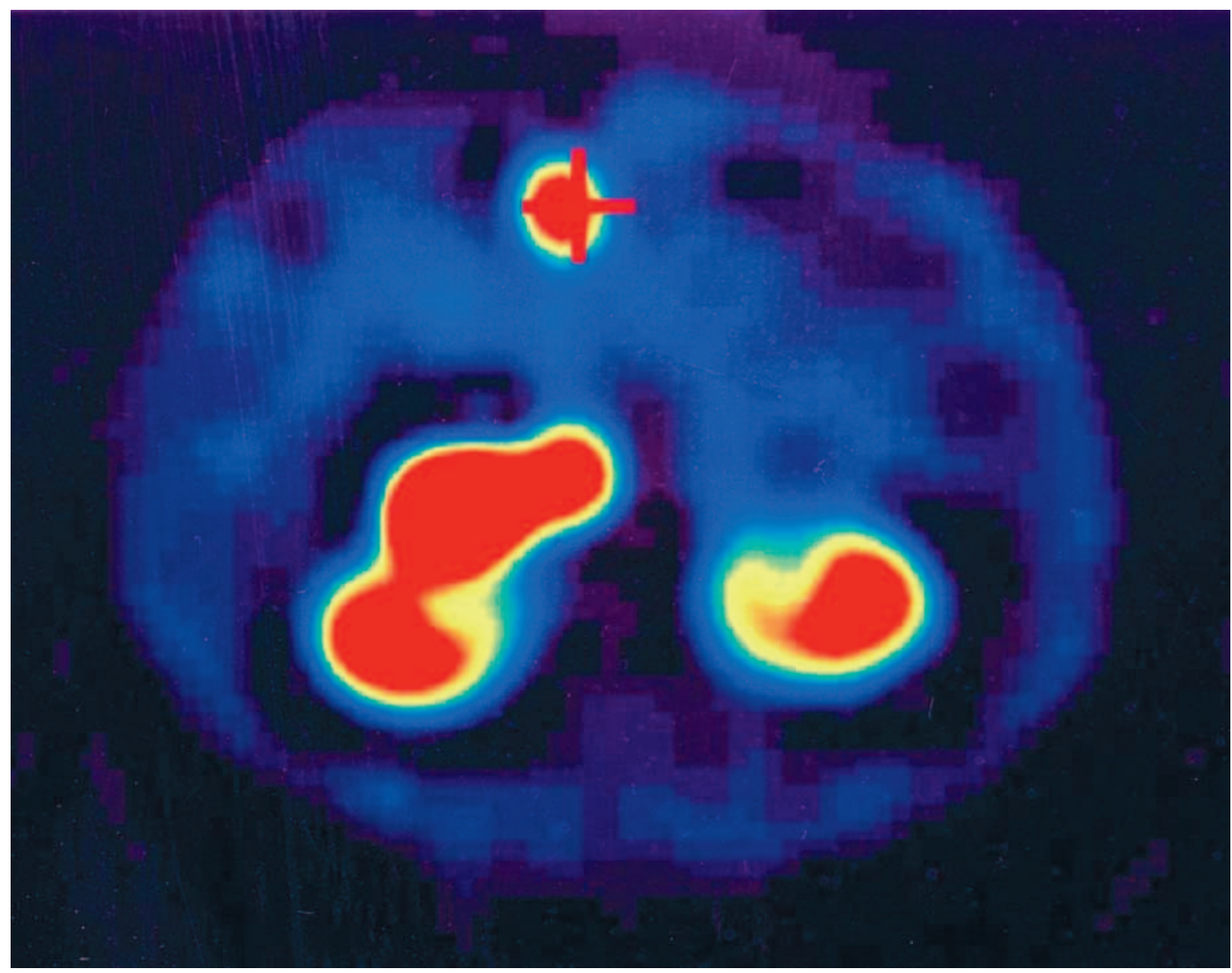

Figure 3 Reconstructed SPECT image of a malignant insulinoma imaged with ${ }^{90} \mathrm{Y}$-octreotide at $24 \mathrm{~h}$. Note that the primary tumour is clearly shown (Indicated by the cross). The radiation from this predominantly $\beta$-emitter is secondary radiation, Bremsstrahlung.

for diagnosis has been coupled to the bifunctional chelating agent (1,4,7,10-tetraazacyclododecane$N, N^{\prime}, N^{\prime \prime}, N^{\prime \prime \prime}$-tetraacetic acid, DOTA ${ }^{0}$ ) for the complexing of ${ }^{90} \mathrm{Y}$ (de Jong et al. 1997, Krenning et al. 1999a) (Fig. 2). In contrast to ${ }^{90} \mathrm{Y}$-DTPA-octreotide, ${ }^{90}$ Y-DOTA-D-Phe ${ }^{1}-$ Tyr $^{3}$-octreotide $\quad\left({ }^{90} \mathrm{Y}\right.$-SMT487, OctreoTher, ${ }^{90}$ Y-DOTATOC) shows no dissociation from the DOTA-chelated peptide in serum and can deliver tumouricidal doses of radiation by targeting SST-positive tumours that have demonstrated uptake on a diagnostic ${ }^{111}$ In-pentetreotide scan (OctreoScan) (de Jong et al. 1997). Furthermore, while, in general, ${ }^{90} \mathrm{Y}$-DOTA-D-Phe ${ }^{1}-\mathrm{Tyr}^{3}$-octreotide is a non- $\gamma$-emitter, the $\beta$-particles can cause localized release of $\gamma$-activity from affected cells (Bremsstrahlung), making some imaging of the effectiveness of therapy possible (Kaltsas et al. 2004a) (Fig. 3).

Initial biodistribution studies indicated that the highest predicted absorbed doses were to the spleen, the kidneys and the tumour, suggesting that high activities of ${ }^{90} \mathrm{Y}$-DOTATOC could be administered with low risk of myelotoxicity, although with potentially high radiation doses to the spleen and kidneys (Cremonesi et al. 1999). In the first clinical results reported by Otte et al. (2002), ${ }^{90}$ Y-DOTATOC was administered as single doses at 6-week intervals (cumulative dose $6120 \pm 1347 \mathrm{MBq} / \mathrm{m}^{2}$ ); five of their patients had non-NET tumours. When the study was concluded, 20 of the 29 patients showed disease stabilization; two, partial remission; four, a reduction in tumour mass of $<50 \%$; and three, progression of tumour growth. Renal and/or haematological toxicity developed in five patients, all of whom received a cumulative dose of $>7400 \mathrm{MBq} / \mathrm{m}^{2}$ (Otte et al. 2002). In a phase II non-randomized study, 37 patients with GEP tumours, the majority of whom had resistant and progressive disease, were treated with four intravenous injections of ${ }^{90} \mathrm{Y}$-DOTA-D-Phe ${ }^{1}-\mathrm{Tyr}^{3}$-octreotide, up 
Table 4 Tumour responses and side-effect profile of treatment using various radiopharmaceuticals based on somatostatin analogues in patients with GEP tumours

\begin{tabular}{|c|c|c|c|c|c|c|}
\hline \multirow[b]{2}{*}{ Radiopharmaceutical } & \multirow[b]{2}{*}{ Reference } & \multirow{2}{*}{$\begin{array}{l}\text { No. of } \\
\text { patients }\end{array}$} & \multicolumn{3}{|c|}{ Tumour response } & \multirow[b]{2}{*}{ Toxicity* } \\
\hline & & & CR/PR & SD & PD & \\
\hline \multirow[t]{3}{*}{${ }^{111} \ln$} & Valkema et al. 2002 & 26 & 0 & $16(61 \%)$ & $10(38 \%)$ & $3(11 \%)$ AML/MDS \\
\hline & Anthony et al. 2002 & 26 & $2(8 \%)$ & $21(81 \%)$ & $3(12 \%)$ & $\begin{array}{l}11 \text { grades } 3-4 \\
\text { haematologic, } \\
3 \text { liver, } 1 \text { renal }\end{array}$ \\
\hline & Buscombe et al. 2003 & 16 & $5(31 \%)$ & 7 (23\%) & $4(25 \%)$ & - \\
\hline \multirow[t]{4}{*}{${ }^{90} \mathrm{Y}$} & Waldherr et al. 2001 & 74 & $18(24 \%)$ & $48(65 \%)$ & $8(11 \%)$ & $\begin{array}{l}8 \% \text { grades } 3-4 \\
1 \text { renal }\end{array}$ \\
\hline & Waldherr et al. 2002 & & & & & \\
\hline & Valkema et al. 2003 & 54 & $4(7 \%)$ & $40(74 \%)$ & $10(19 \%)$ & $\begin{array}{l}38 \% \text { grades } 3-4 \\
\text { haematological, } \\
1 \mathrm{MDS}, 1 \text { liver, } \\
1 \text { renal }\end{array}$ \\
\hline & Bodei et al. 2004b & 141 & $(26 \%)$ & $(55 \%)$ & $(18 \%)$ & \\
\hline${ }^{177} \mathrm{Lu}$ & Kwekkeboom et al. 2005 & 131 & $35(28 \%)$ & $68(54 \%)$ & $22(18 \%)$ & $\begin{array}{l}\text { Up to } 1.5 \% \text { grade } 3 \\
\text { haematological, } \\
1 \text { liver, } 1 \text { renal }\end{array}$ \\
\hline
\end{tabular}

CR: complete response; PR: partial response; SD: stable disease; PD: progressive disease;

AML: acute myeloid leukaemia; MDS: myelodysplastic syndrome.

${ }^{*}$ Assessment followed WHO criteria (grades 3-4 toxicity is presented only).

to a total of $6000 \mathrm{MBq}(160 \mathrm{mCi}) / \mathrm{m}^{2}$ (Waldherr et al. 2001). An objective tumour response rate of $24 \%$ (36\% for pancreatic tumours) was noted, without serious toxicity. The same group evaluated the response of GEP tumours to high-dose, targeted irradiation with $7.4 \mathrm{GBq} / \mathrm{m}^{2}$ of the radiolabelled SST analogue, concluding that high-dose, targeted radiotherapy with ${ }^{90} \mathrm{Y}$-DOTATOC is a well-tolerated treatment, showing an objective tumour response of $23 \%$ according to WHO criteria (38\% for pancreatic tumours) (Waldherr et al. 2002). A similar tumour response rate $(28 \%, 5 \%$ of which were a complete response) was obtained in a study of 87 patients with NETs who were treated with a cumulative activity of $7.4-20.3 \mathrm{GBq} / \mathrm{m}^{2}$; no major adverse effects were noted up to a dose of $5.55 \mathrm{GBq} /$ cycle (Paganelli et al. 2002). In different phase I trials involving the administration of ${ }^{90} \mathrm{Y}$-DOTA $\mathrm{Tyr}^{3}$ octreotide in patients with NETs, an overall antimitotic effect with a $20 \%$ partial response and $60 \%$ disease stabilization was observed, even though the maximum cumulative dose $(26 \mathrm{GBq})$ failed to reach the maximum tolerable dose (de Jong et al. 2002). Recent data presented by Bodei et al. $(2004 a)$ on ${ }^{90}$ Y-DOTATOC in 141 patients with mainly NETs, who were treated with a cumulative activity of $7.4-26.4 \mathrm{GBq}$, suggested an overall objective response rate (partial and complete) of $26 \%$. When the authors subdivided patients according to the state of disease at the time of enrolment, an overall clinical benefit (complete and partial response and stable disease) was observed in $76 \%$, whereas complete and partial responses were evident in $32 \%$ of cases. The duration of response was 2-59 months, and the majority of responders had GEP tumours (Bodei et al. 2004a). Treatment with ${ }^{90} \mathrm{Y}$-DOTATOC was also associated with an improvement in patients' well-being and overall improved quality of life (QoL) (Bushnell et al. 2003b).

Despite differences between the several protocols used, most of the studies using ${ }^{90} \mathrm{Y}$-DOTATATE have demonstrated tumour responses of $10-30 \%$ (mean $25 \%$ ), considerably higher than those obtained with ${ }^{111}$ In-DTPA (Table 4). These differences could be attributed either to differences in administered doses and dosage schemes between the various studies or, more likely, to differences in patient characteristics (percentage of radionuclide uptake, estimated total tumour burden and extent of liver involvement). In addition, several studies have included different types of NETs with considerable differences in the density of SSTRs and natural history. As already mentioned, when response is considered according to the various types of NETs, it becomes evident that patients with GEP tumours exhibit a more favourable response, 36-38\%, than other NETs treated with the same radiopharmaceuticals (Waldherr et al. 2001, Bodei et al. 2004a, Kwekkeboom et al. 2005) (Table 4). 


\section{Peptide receptor radionuclide therapy with ${ }^{90} \mathrm{Y}$-lanreotide}

In contrast to ${ }^{111}$ In-DTPA-D-Phe ${ }^{1}$-octreotide, which binds to $\mathrm{SSTR}_{2}$ and $\mathrm{SSTR}_{5}$ with high affinity, binds to $\mathrm{SSTR}_{3}$ with moderate affinity, and does not bind to $\mathrm{SSTR}_{1}$ and $\mathrm{SST}_{4},{ }^{111} \mathrm{In}$ - and ${ }^{90} \mathrm{Y}$-DOTA-lanreotide was found to bind to $\mathrm{SSTR}_{2-4}$ and $\mathrm{SST}_{5}$ with high affinity, and to $\mathrm{SSTR}_{1}$ with low affinity (Virgolini et al. 2002a). Based on this unique binding profile, ${ }^{111}$ In-DOTAlanreotide was considered a potential radioligand for tumour diagnosis, and, consequently, ${ }^{90}$ Y-DOTAlanreotide was considered for receptor-mediated radionuclide therapy (Virgolini et al. 2002a,b). Leimer et al. (1998) initially reported a $25 \%$ regression of liver metastasis and substantial symptomatic improvement in a patient with a malignant gastrinoma after four infusions of $1 \mathrm{GBq}{ }^{90} \mathrm{Y}$-lanreotide. Following that observation, the phase IIa Multicentre Analysis of a Universal Receptor Imaging and Treatment Initiative (MAURITIUS) European study was organized, in which 39 patients with GEP tumours (34 carcinoid tumours) were included (Virgolini et al. 2002a). After two cycles of ${ }^{90} \mathrm{Y}$-DOTA-lanreotide, the treatment was discontinued in the presence of progressive disease; otherwise, a further two cycles were given. Over a 3-year follow-up period, $20.5 \%$ of patients achieved regression of their disease, whereas $43.6 \%$ demonstrated stable disease. However, the fact that ${ }^{90} \mathrm{Y}$-DOTATOC exhibits higher tumour uptake in patients with NET lesions than lanreotide suggests that, where available, it should be the treatment of first choice (Virgolini et al. 2002b).

A few patients with malignant chromaffin cell tumours have been treated with ${ }^{111}$ In-DTPAoctreotide and ${ }^{90} \mathrm{Y}$-DOTATOC, some obtaining disease stabilization (Waldherr et al. 2001, Valkema et al. 2002). A few patients with medullary carcinoma of the thyroid (MTC) also received ${ }^{111}$ In-octreotide or ${ }^{90} \mathrm{Y}$-lanreotide in the MAURITIUS trial (Krenning et al. 1999a, Virgolini et al. 2002b, Buscombe et al. 2003). Although this was a heterogeneous group of patients, initial results were encouraging, supporting further prospective studies of the use of this therapy in patients with advanced MTC (Krenning et al. 1999a, Virgolini et al. 2002b, Buscombe et al. 2003).

\section{Peptide receptor radionuclide therapy with [ ${ }^{177}$ Lu-DOTA-Tyr ${ }^{3}$ ]octreotate}

In order to overcome the limitations of administering tumoricidal doses of radiotherapy to non-octreotideavid lesions, and the lack of uptake to certain areas due to tumour heterogeneity, several $\beta$-emitters, in addition to ${ }^{90} \mathrm{Y}$, such as ${ }^{153} \mathrm{Sm},{ }^{177} \mathrm{Lu}$ and ${ }^{186} \mathrm{Re}$, have also been considered, usually in combination with $\mathrm{Tyr}^{3}$-octreotate (DOTATE), which exhibits the highest affinity for $\mathrm{SSTR}_{2}$ (de Jong et al. 2002). Initial studies reported a ninefold increase in the affinity for $\mathrm{SST}_{2}$ of DOTA $\mathrm{Tyr}^{3}$-octreotate compared with DOTA$\mathrm{Tyr}^{3}$-octreotide, which remained six- to seven-fold higher when ${ }^{90} \mathrm{Y}$ was also added to the complex (Reubi et al. 2005). Besides the higher tumour uptake, $\mathrm{Tyr}^{3}$-octreotate exerts similar kidney uptake to $\mathrm{Tyr}^{3}$-octreotide, leading to a better tumour:kidney ratio; however, $\mathrm{Tyr}^{3}$-octreotide exhibits faster renal clearance, and this could in theory mean lower bone-marrow irradiation (de Jong et al. 2002). The relative advantages of ${ }^{177} \mathrm{Lu}$ over ${ }^{90} \mathrm{Y}$ include also the emission of $\gamma$-radiation, which makes it available for scintigraphy/dosimetry, and the shorter range of $\beta$-particles, by which higher radiation can be delivered to smaller tumours (de Jong et al. 2003). Therefore, ${ }^{177} \mathrm{Lu}$-DOTA-Tyr ${ }^{3}$-octreotate may well represent a radiopharmaceutical advance, as it can achieve higher absorbed doses for most tumours with similar doses to dose-limiting organs because of the lower tissue-penetration range than ${ }^{90}$ Y-DOTATOC, a feature particularly important for smaller lesions (de Jong et al. 2003).

An initial study assessed the effects of ${ }^{177}$ Lu-DOTA$\mathrm{Tyr}^{3}$-octreotate therapy on tumours of various sizes in 34 patients with GEP tumours (Kwekkeboom et al. 2003). Three months after the final administration, complete remission was found in one patient $(3 \%)$, partial remission in $12(35 \%)$ patients, stable disease in $14(41 \%)$ patients and progressive disease in seven $(21 \%)$ patients. The outcome of radionuclide therapy was positively correlated with a high uptake on the OctreoScan, limited hepatic tumour mass and high performance status (Kwekkeboom et al. 2003). The authors also noted that responding patients had a limited tumour load, thus indicating early employment of receptor radionuclide therapy in patients with GEP tumours, without waiting for tumour progression (Kwekkeboom et al. 2003). The same group have recently assessed the effect of ${ }^{177} \mathrm{Lu}-\mathrm{DOTA}-\mathrm{Tyr}^{3}$ octreotate on the self-reported QoL in patients with metastatic GEP tumours (Teunissen et al. 2004). The global health/QoL, as well as several function and symptom scales, was significantly improved after ${ }^{177}$ Lu-DOTA-Tyr ${ }^{3}$-octreotate therapy even in patients with progressive disease (Teunissen et al. 2004). More recently, the results of 131 patients with GEP tumours treated with a cumulative dose of $22.2-29.6 \mathrm{GBq}$ of ${ }^{177}$ Lu-DOTA-Tyr ${ }^{3}$-octreotate became available: three 
patients $(2 \%)$ obtained complete remission; $32(26 \%)$, partial remission; 24 (19\%), a minor response (tumour diameter decrease of $25-50 \%)$; and $44(35 \%)$, stable disease. Twenty-two (18\%) patients developed tumour progression. Serious side effects were rare, only a single patient developing acute renal failure and one developing hepatorenal syndrome, whereas the median time to progression for patients who either responded or remained stable was 36 months (Kwekkeboom et al. 2005). Patients who obtained lower remission rates and/or progression of their disease had lower uptake on the diagnostic ${ }^{111}$ In-octreotide scan, more extensive disease and hepatic involvement, and worse performance status. These results compare favourably to the ones obtained in patients treated with chemotherapy, and imply that treatment efficacy is probably related to early initiation of treatment when tumour load is limited (Kwekkeboom et al. 2005). A further finding of the latest study favours the early administration of treatment with radiopharmaceuticals, as disease stability or progression before the initiation of treatment did not affect the response to treatment (Kwekkeboom et al. 2003).

From these studies, where several different radiopharmaceuticals have been used for the treatment of NETs, it seems that ${ }^{177}$ Lu-DOTA-Tyr ${ }^{3}$-octreotate represents a major advance in the field of treatment with radiopeptides. However, it must be emphasized that direct, randomized, comparative studies of the various forms of radiopharmaceuticals used are lacking.

\section{Combination treatment with ${ }^{90} \mathrm{Y}$-DOTATOC and ${ }^{177}$ Lu-DOTA-Tyr ${ }^{3}$-octreotate}

When we consider the individual radiobiological features of the $\beta$-emitters ${ }^{177} \mathrm{Lu}$ and ${ }^{90} \mathrm{Y}$, it becomes evident that each has specific potential advantages for tumour therapy (Tables $1 \& 2$ ). ${ }^{90} \mathrm{Y}$ particles have higher energies and longer ranges, leading to the deposition of more radioactivity in tumour cell per peptide molecule and to a better crossfire throughout the tumour; in addition, the relatively short half-life of ${ }^{90} \mathrm{Y}$ leads to a higher dose rate. These properties make it more favourable for the treatment of larger tumours and for tumours with heterogeneous receptor distribution (de Jong et al. 2005). However, smaller tumours are less suitable for treatment with ${ }^{90} \mathrm{Y}$, as they will not absorb all the energy emitted from ${ }^{90} \mathrm{Y}$ in the tumour cells, whereas adjacent healthy tissue will absorb relatively high doses and will be exposed to toxicity (Krenning et al. 2004). In contrast, ${ }^{177} \mathrm{Lu}$ particles that have lower energy and a smaller particle range are associated with better absorption in smaller tumours, and enable scintigraphy, as they emit $\gamma$-radiation (de Jong et al. 2005). Therefore, to treat patients with tumours of various sizes and non-homogeneous receptor distribution, the combination of the highenergy ${ }^{90} \mathrm{Y}$ for the larger lesions and the low-energy ${ }^{177} \mathrm{Lu}$ for the smaller lesions and metastases seems a reasonable approach. Animal studies have documented that this combination $\left({ }^{90} \mathrm{Y}\right.$ and $\left.{ }^{177} \mathrm{Lu}\right)$ provides different $\beta$-energies and particle ranges that achieve higher cure rates in tumours of various sizes than either radionuclide alone (de Jong et al. 2005). These results also agree with the prediction of a mathematical model that was used to assess tumoral response to different $\beta$-emitting particles in relation to tumour size, and that suggested an optimal tumour diameter of $34 \mathrm{~mm}$ for ${ }^{90} \mathrm{Y}$ and $2 \mathrm{~mm}$ for ${ }^{177} \mathrm{Lu}$ (O'Donoghue et al. 1995). Another interesting option is the sequential treatment of these tumours with these analogues, initially administering ${ }^{90} \mathrm{Y}$-labelled analogues to treat larger lesions followed by ${ }^{177} \mathrm{Lu}$-labelled analogues to treat smaller metastases (de Jong et al. 2005).

\section{Predictors of response}

Despite variations of the protocols used, objective tumour size responses of approximately $25 \%$ (range $10-30 \%$ ) have been obtained in studies using ${ }^{90}$ Y-DOTATOC (Chinol et al. 2002, Waldherr et al. 2002, Bodei et al. 2003, Valkema et al. 2005), and approximately $30 \%$ in those using ${ }^{177} \mathrm{Lu}-$ ${ }^{177}$ Lu-DOTA-Tyr ${ }^{3}$-octreotate (DOTATATE) (Krenning et al. 2005, Kwekkeboom et al. 2005, Pauwels et al. 2005). This rather low response rate may be related to the relative radioresistance of NETs, but probably also reflects the absence of uniform criteria in patient selection (Bodei et al. 2004b, Pauwels et al. 2005). It is therefore important to establish predictive parameters to select patients likely to benefit from treatment with these radiopeptides and identify those not likely to respond. As shown from data derived from patients with NETs treated with ${ }^{131}$ I-MIBG, important predictors of the outcome of therapy with this radionuclide are the extent of the disease and the total tumour load (Chatal et al. 2000, Mukherjee et al. 2001). Similarly, tumour regression was positively correlated with high level of uptake on OctreoScan imaging, limited hepatic tumour mass and high Karnofsky performance score (Kwekkeboom et al. 2003). There is also evidence of a significant correlation 
Table 5 Patient selection criteria for targeted radiotherapy

\begin{tabular}{ll}
\hline Indications & Contraindications \\
\hline Inoperable/metastatic GEP & Myelosuppression \\
Increased uptake & Bone-marrow metastatic \\
at tumour sites & disease \\
Haematological & Renal impairment \\
considerations* & Extensive hepatic \\
$\mathrm{Hb}>10 \mathrm{~g} / \mathrm{l}$ & involvement \\
$\mathrm{WBC}>3.0 \times 10^{*} / \mathrm{l}$ & Poor performance \\
$\mathrm{PLT}>100 \times 10^{9} / \mathrm{l}$ & status \\
Biochemical considerations & Pregnancy/lactation \\
Urea $<10 \mathrm{mmol} / \mathrm{l}$ & Previous therapy with \\
Creatinine $<160 \mu \mathrm{mol} / \mathrm{l}$ & radiopharmaceutical \\
GFR $>40 \mathrm{ml} / \mathrm{min}$ & Exceeding a dose limit \\
Good performance & \\
status &
\end{tabular}

$\mathrm{Hb}$, haemoglobin; WBC, white blood cells; PLT, platelets; GFR, glomerular filtration rate; GEP, gastroenteropancreatic tumours.

${ }^{*}$ Attention is required in patients previously treated with chemotherapy.

between dose estimates of tumours and tumour size reduction that is measured at the end of the treatment; the median absorbed dose was sixfold higher in responding than non-responding tumours (Pauwels et al. 2005). Although tumour dosimetry did not completely distinguish responders from non-responders, it may be useful in the management of patients with NETs. It has therefore been suggested that early treatment (particularly in patients with progressive disease) may be associated with better outcome (Kwekkeboom et al. 2003). The fact that progression during or after treatment was more frequent in patients with extensive tumour load, particularly in the liver, implies that a more aggressive approach may be more appropriate than a 'wait-and-see' approach, as this might be associated with worse outcome (Kwekkeboom et al. 2003). In addition, future studies should provide evidence-based information on the optimal time to treat with radiopeptides with respect to other forms of treatment, and whether disease stability should be regarded as response to treatment, particularly in the group of patients with progressive disease following other forms of treatment (Bodei et al. 2004b). However, we now have sufficient information to suggest rational indications for the possible use of this type of treatment (Table 5).

\section{Radioembolization}

NETs show a particular predisposition for hepatic metastases that receive most of their blood supply from the hepatic artery (Kaltsas et al. 2004a). Radioembolization implies the administration of microspheres labelled with radioactive isotopes that induce hepatic artery occlusion and simultaneously local irradiation (brachyradiotherapy). In a preliminary phase I study, six patients with metastatic NETs were enrolled, and glass microspheres loaded with ${ }^{90} \mathrm{Y}$ were administered for radioembolization (Andrews et al. 1994). Although some beneficial results were obtained, problems with dosimetry due to difficulties in calculating the exact volume of liver metastases and the inhomogeneous distribution of the microspheres have limited their use (Andrews et al. 1994). More recently, ${ }^{111}$ In-octreotide has been advocated as an alternative; direct intra-arterial injection achieves higher intratumoral concentrations and may be of value in treating isolated hepatic and/or cerebral lesions but is less helpful in the management of disseminated disease (Lewington 2003).

\section{Safety and side effects}

Biodistribution studies demonstrated that the highest predicted absorbed doses were to the spleen, kidneys and the tumour. Preliminary studies showed that since no spleen toxicity was demonstrated, the kidneys are the critical organs, particularly as octreotide is mainly excreted by the kidneys (Bodei et al. 2003, Pauwels et al. 2005). After being filtered by glomeruli, radiopeptides are reabsorbed and retained from the proximal tubule; renal toxicity occurs because of irradiation of the radiosensitive glomeruli by activity retained in the relatively radioresistant tubular cells, the main histological finding being thrombotic microangiopathy (Otte et al. 2002, Pauwels et al. 2005). The cumulative absorbed dose to the kidney may cause renal damage when it exceeds the conventional threshold of $23-25 \mathrm{~Gy}$; although this threshold is derived from experience obtained from external irradiation, cases of several renal failure have been found to follow treatment with radiopharmaceuticals (Cybulla et al. 2001, Otte et al. 2002). Adjustments of the threshold dose by the linear-quadratic method has estimated the renal threshold toxicity dose to be $35 \pm 7$ Gy for ${ }^{90} \mathrm{Y}$-DOTATOC (Konijnenberg 2003). Although renal uptake may vary considerably in patients undergoing dosimetry, this can be substantially improved when the actual kidney volume (as estimated by CT) is taken into consideration (Pauwels et al. 2005). Retrospective analysis of patients who have developed renal toxicity revealed that this occurred in patients who had the smaller kidneys (received higher radiation doses per ml) (Pauwels et al. 
2005, Valkema et al. 2005). In addition, methods to reduce kidney uptake and thus avoid acute and/or delayed renal toxicity have been developed (Pauwels et al. 2005, Valkema et al. 2005). Positively charged amino acids, such as L-lysine and/or L-arginine, have been shown to completely inhibit proximal tubular reabsorption of the radiopeptides, thus resulting in a potential deduction in the renal dose. Different regimens of amino-acid co-infusion with a $27 \%$ mean reduction (range $20-40 \%$ ) in the renal absorbed dose and no effect on tumoral uptake have been described; no further cases of renal insufficiency have been described in studies treating a considerable number of patients with NETs with this regimen (Bodei et al. 2004a, Pauwels et al. 2005, Valkema et al. 2005).

Renal toxicity was not the only parameter to be considered. Recent studies have shown that SST analogues are also taken up from the bone marrow, but not the trabecular cortical bone; although cases of bone-marrow toxicity were described in the initial studies, several subsequent studies treating a large number of patients failed to confirm these data (Bodei et al. 2004a, Pauwels et al. 2005). However, the possibility of a mild but progressive deficiency in bone-marrow reserves has to be considered, and this form of treatment should probably not be administered to patients with metastatic disease involving the bone marrow extensively (Bodei et al. 2004a). Following the development of acute hepatic toxicity in patients with extensive hepatic involvement, Bushnell et al. (2003a) studied 12 patients with extensive hepatic metastases (defined as $25 \%$ or more) who were treated with ${ }^{90} \mathrm{Y}$-DOTATOC. Only four patients developed a significant elevation of hepatic enzymes, suggesting that such patients can be treated with a cumulatively administered activity of $360 \mathrm{mCi}$ of ${ }^{90} \mathrm{Y}$-DOTATOC with only a small chance of developing mild, acute or subacute hepatic radiation damage (Bushnell et al. 2003a). Neither endocrine dysfunction of the pituitary axis nor diabetes mellitus has been observed after treatment with radiopharmaceuticals (Bodei et al. 2004a); however, transient impairment of spermatogenesis has been described (de Jong et al. 2002).

\section{Future prospects}

Targeting antigens or receptors that are overexpressed in tumour cells compared with the expression in normal cells, or exploiting uptake mechanisms, has been the basis for therapy with radiopharmaceuticals. To optimize their effect, this form of treatment should be used in patients with small tumour targets (not more than $1-2 \mathrm{~cm}$ in diameter) (de Jong et al. 2002).
For large, macroscopic targets, internal radiotherapy is probably inefficient because of the low, heterogeneous tumour uptake (Krenning et al. 2005). Combination therapy with both ${ }^{131} \mathrm{I}$-MIBG and ${ }^{90} \mathrm{Y}$-DOTATATE or the combinations of ${ }^{111} \mathrm{In} /{ }^{90} \mathrm{Y} /{ }^{177} \mathrm{Lu}$-octreotide remains an attractive theoretical option, after as complete a surgical resection as possible, to ensure good uptake of the radiopharmaceutical by the remaining tumour target (Krenning et al. 2005, Larson \& Krenning 2005). If treatments are repeated regularly, it is likely that the disease can be at least stabilized for a period of several years, if not cured (Kaltsas et al. 2004a).

In addition, newer SST analogues in combination with different emitters are in development that might exhibit superior imaging and therapeutic properties. SOM230 (Novartis, Basel, Switzerland) is a newly developed SST analogue that binds with high affinity to $\mathrm{SSTR}_{1-3}$ and $\mathrm{SSTR}_{5}$, but not SSTR 4 (Bruns et al. 2002, de Herder et al. 2003). Its potential use as a radiopharmaceutical is awaited with interest. In addition, new drugs interacting with multireceptor family cross-talk, particularly SSTRs, are being developed; these SST subtype homo- or heterodimers may exert properties distinct from the individual receptors in terms of internalization and functional activity (de Herder et al. 2003). Hybrid somatostatin-dopamine molecules with high affinity to SSTR 2 and $\mathrm{D}_{2}$ receptors have been developed and are expected to have a higher affinity than each receptor alone in NETs that express them (de Herder et al. 2003).

Apart from expressing SSTRs, GEP tumours can express several other receptors such as glucagonlike peptide 1 (GLIP-1) receptors, cholecystokinin receptors, and bombesin or vasoactive intestinal peptide (VIP) receptors (Reubi \& Waser 2003). Thus, insulinomas have more GLIP-1 receptors than SSTRs whereas carcinoid tumours also express cholecystokinin 2, bombesin and/or VIP receptors (Reubi 2004). The concomitant expression of several of these peptide receptors in GEP tumours forms the basis for in vivo multireceptor targeting of those tumours, using a combination of radiolabelled compounds (de Jong et al. 2003, Reubi et al. 2005). Such an approach may increase the accumulation of radioactivity in these tumours, improving further targeting efficacy, and it may also allow different radioligands to be labelled with isotopes of different ranges in order to obtain optimal radiotherapy for lesions of various size. Radiolabelled minigastrin analogues have already been applied successfully in cholecystokinin 2 receptorpositive tumours, such as MTC (de Jong et al. 2003, Reubi 2005). 
Compounds such as RGD (Arg-Gly-Asp) peptides have been described as antagonizing tumour angiogenesis by binding to $a_{v} \beta_{3}$ receptors on newly formed blood vessels. These compounds may be combined with DTPA-Tyr ${ }^{3}$-octreotate and form hybrid peptides that can bind to both $\operatorname{SSTR}_{2}$ and $\mathrm{a}_{\mathrm{v}} \beta_{3}$ receptors and can thus be used for both scintigraphy and radionuclide therapy (van Hagen et al. 2000). Co-administration of chemotherapeutic drugs with radiosensitizing properties may act synergistically with irradiation, improving the efficacy of therapy with radiopharmaceuticals (Chatal et al. 2000). Immune system activation for the control of micrometastatic disease may play an additional role in pursuit of complete control and cure. Finally, transfer of genes encoding for the expression of $\mathrm{SSTR}_{2}$ and $\mathrm{SSTR}_{5}$ to receptor-negative tumours may render them responsive to treatment with these agents, including radiolabelled compounds (de Herder et al. 2003, Kaltsas et al. 2004b).

\section{Multidisciplinary approach}

Patients with cancer and particularly patients with GEP tumours (due to their prolonged survival in the face of extensive disease) greatly benefit from a multidisciplinary therapeutic approach. Such teams should include physicians with a special interest in NETs, pathologists, endocrinologists, gastroenterologists, interventional radiologists, surgeons, oncologists and nuclear medicine experts. Diagnostic procedures should be critically reviewed to help establish a consensus on the best evidence-based management, including invasive procedures such as chemoembolization or repeated surgical procedures. The integration of receptor therapy with SST analogue (octreotide and lanreotide)-based radiopharmaceuticals and biotherapy (long-acting SST analogues with or without IFN- $\alpha$ ), together with other therapeutic approaches, must be explored. As a rule, surgical debulking of the primary tumour and reduction of hepatic deposits should be the first-line treatment; the optimal approach must be considered in each patient in order to improve survival and maintain good QoL (Kaltsas et al. 2004b). Attempts to improve QoL should be sought, as patients with metastatic disease may still experience prolonged survival, and this should be weighed against the potential side effects of any systemic treatment. Since the majority of these tumours grow slowly and even patients with disseminated disease may have prolonged survival, early involvement in palliative team programmes may be helpful. In order to evaluate the results of current management, establish guidelines and develop new therapeutic trials, multicentre collaborations are particularly helpful.

\section{Summary}

Treatment with radiolabelled SST analogues is an evolving therapeutic modality for the management of patients with inoperable or metastasized neuroendocrine, particularly GEP, tumours. Prerequisities for treatment success include demonstration of high tumour uptake relative to non-target tissues on quantitative, diagnostic radionuclide imaging (e.g. OctreoScan) and stable haematological and biochemical function. Although there is a need for more accurate prediction of the absorbed doses, treatment with all ${ }^{111} \mathrm{In}-,{ }^{90} \mathrm{Y}$ - or ${ }^{177} \mathrm{Lu}$-labelled SS analogues has been associated with considerable symptomatic improvement with limited side effects that are mainly related to kidney function. Targeted therapies are better tolerated than other systemic treatments and deliver higher absorbed radiation doses to the tumour than can be achieved by external beam irradiation. The results obtained with ${ }^{90} \mathrm{Y}$-DOTA $\left.{ }^{0}, \mathrm{Tyr}^{3}\right]$-octreotide and $\left[{ }^{177} \mathrm{Lu}\right.$-DOTA $\left.{ }^{0}, \mathrm{Tyr}^{3}\right]$-octreotate have also exhibited substantial tumour regression, whereas the combination of these two radiopeptides may be even more effective than either alone. Future directions for improving this type of therapy include multireceptor targeting, attempts to upregulate SSTR expression on tumours and the use of radiosensitizers.

\section{Acknowledgements}

The authors declare that there is no conflict of interest that would prejudice the impartiality of this scientific work.

\section{References}

Andrews JC, Walker SC, Ackermann RJ, Cotton LA, Ensminger WD \& Shapiro B 1994 Hepatic radioembolization with yttrium-90 containing glass microspheres: preliminary results and clinical follow-up. Journal of Nuclear Medicine 35 1637-1644.

Anthony LB, Woltering EA, Espenan GD, Cronin MD, Maloney TJ \& McCarthy KE 2002 Indium-111pentetreotide prolongs survival in gastroenteropancreatic malignancies. Seminars in Nuclear Medicine 32 123-132.

Arnold R, Frank M \& Kajdan U 1994 Management of gastroenteropancreatic endocrine tumors: the place of somatostatin analogues. Digestion 55 (Suppl 3) 107-113.

Barone R, Borson-Chazot F, Valkema R, Walrand S, Chauvin F, Gogou L, Kvols LK, Krenning EP, Jamar F \& Pauwels S 2005 Patient-specific dosimetry in predicting 
renal toxicity with (90)Y-DOTATOC: relevance of kidney volume and dose rate in finding a dose-effect relationship. Journal of Nuclear Medicine 46 (Suppl 1) 99S-106S.

Bodei L, Cremonesi M, Zoboli S, Grana C, Bartolomei M, Rocca P, Caracciolo M, Macke HR, Chinol M \& Paganelli G 2003 Receptor-mediated radionuclide therapy with ${ }^{90}$ Y-DOTATOC in association with amino acid infusion: a phase I study. European Journal of Nuclear Medicine and Molecular Imaging 30 207-216.

Bodei L, Cremonesi M, Grana C, Rocca P, Bartolomei M, Chinol M \& Paganelli G 2004a Receptor radionuclide therapy with ${ }^{90} \mathrm{Y}$-[DOTA $]^{0}-\mathrm{Tyr}^{3}$-octreotide $\left({ }^{90} \mathrm{Y}\right.$-DOTATOC) in neuroendocrine tumours. European Journal of Nuclear Medicine and Molecular Imaging 31 1038-1046.

Bodei L, Handkiewicz-Junak D, Grana C, Mazzetta C, Rocca P, Bartolomei M, Lopera SM, Cremonesi M, Chinol M, Macke HR \& Paganelli G 2004b Receptor radionuclide therapy with ${ }^{90} \mathrm{Y}$-DOTATOC in patients with medullary thyroid carcinomas. Cancer Biotherapy and Radiopharmaceuticals 19 65-71.

Bruns C, Lewis I, Briner U, Meno-Tetang G \& Weckbecker G 2002 SOM230: a novel somatostatin peptidomimetic with broad somatotropin release inhibiting factor (SRIF) receptor binding and a unique antisecretory profile. European Journal of Endocrinology 146 707-716.

Buscombe JR, Caplin ME \& Hilson AJ 2003 Long-term efficacy of high-activity ${ }^{111}$ In-pentetreotide therapy in patients with disseminated neuroendocrine tumors. Journal of Nuclear Medicine 44 1-6.

Bushnell D, Menda Y, Madsen M, O’Dorisio T, Carlisle T, Zehr P, Ponto L, Karwal M, Parker S, Ponto J, Connolly M \& Bouterfa H $2003 a$ Assessment of hepatic toxicity from treatment with ${ }^{90} \mathrm{Y}$-SMT 487 (OctreoTher(TM)) in patients with diffuse somatostatin receptor positive liver metastases. Cancer Biotherapy and Radiopharmaceuticals 18 581-588.

Bushnell D, O’Dorisio T, Menda Y, Carlisle T, Zehr P, Connolly M, Karwal M, Miller S, Parker S \& Bouterfa H $2003 b$ Evaluating the clinical effectiveness of ${ }^{90} \mathrm{Y}$-SMT 487 in patients with neuroendocrine tumors. Journal of Nuclear Medicine 44 1556-1560.

Chatal JF, Le Bodic MF, Kraeber-Bodere F, Rousseau C \& Resche I 2000 Nuclear medicine applications for neuroendocrine tumors. World Journal of Surgery 24 $1285-1289$.

Chinol M, Bodei L, Cremonesi M \& Paganelli G 2002 Receptor-mediated radiotherapy with Y-DOTA-DPhe-Tyr-octreotide: the experience of the European Institute of Oncology Group. Seminars in Nuclear Medicine 32 141-147.

Cremonesi M, Ferrari M, Zoboli S, Chinol M, Stabin MG, Orsi F, Maecke HR, Jermann E, Robertson C, Fiorenza M, Tosi G \& Paganelli G 1999 Biokinetics and dosimetry in patients administered with
(111)In-DOTA-Tyr(3)-octreotide: implications for internal radiotherapy with (90)Y-DOTATOC. European Journal of Nuclear Medicine 26 877-886. Cybulla M, Weiner SM \& Otte A 2001 End-stage renal disease after treatment with ${ }^{90}$ Y-DOTATOC. European Journal of Nuclear Medicine 28 1552-1554.

de Herder WW, Hofland LJ, van der Lely AJ \& Lamberts SW 1996 Peptide receptors in gut endocrine tumours. Bailliere's Clinical Gastroenterology 10 571-587.

de Herder WW, Hofland LJ, van der Lely AJ \& Lamberts SW 2003 Somatostatin receptors in gastroentero-pancreatic neuroendocrine tumours. Endocrine-Related Cancer 10 451-458.

de Jong M, Bakker WH, Krenning EP, Breeman WA, van der Pluijm ME, Bernard BF, Visser TJ, Jermann E, Behe M, Powell P \& Macke HR 1997 Yttrium-90 and indium-111 labelling, receptor binding and biodistribution of $\left[\right.$ DOTA $^{0}$,d-Phe1, Tyr $^{3}$ ]octreotide, a promising somatostatin analogue for radionuclide therapy. European Journal of Nuclear Medicine 24 368-371.

de Jong M, Valkema R, Jamar F, Kvols LK, Kwekkeboom DJ, Breeman WA, Bakker WH, Smith C, Pauwels S \& Krenning EP 2002 Somatostatin receptor-targeted radionuclide therapy of tumors: preclinical and clinical findings. Seminars in Nuclear Medicine 32 133-140.

de Jong M, Kwekkeboom D, Valkema R \& Krenning EP 2003 Radiolabelled peptides for tumour therapy: current status and future directions. Plenary lecture at the EANM 2002. European Journal of Nuclear Medicine and Molecular Imaging 30 463-469.

de Jong M, Breeman WA, Valkema R, Bernard BF \& Krenning EP 2005 Combination radionuclide therapy using ${ }^{177} \mathrm{Lu}$ - and ${ }^{90} \mathrm{Y}$-labeled somatostatin analogs. Journal of Nuclear Medicine 46 (Suppl 1) 13S-17S.

Forssell-Aronsson E, Bernhardt P, Nilsson O, Tisell LE, Wangberg B \& Ahlman H 2004 Biodistribution data from 100 patients i.v. injected with

${ }^{111}$ In-DTPA-D-Phe1-octreotide. Acta Oncologia 43 436-442.

Kaltsas G, Mukherjee JJ, Plowman PN \& Grossman AB $2001 a$ The role of chemotherapy in the nonsurgical management of malignant neuroendocrine tumours. Clinical Endocrinology 55 575-587.

Kaltsas GA, Mukherjee JJ \& Grossman AB $2001 b$ The value of radiolabelled MIBG and octreotide in the diagnosis and management of neuroendocrine tumours. Annals of Oncology 12 (Suppl 2) S47-S50.

Kaltsas G, Rockall A, Papadogias D, Reznek R \& Grossman AB 2004b Recent advances in radiological and radionuclide imaging and therapy of neuroendocrine tumours. European Journal of Endocrinology 151 15-27.

Kaltsas GA, Besser GM \& Grossman AB 2004b The diagnosis and medical management of advanced neuroendocrine tumors. Endocrine Reviews 25 458-511.

Kassis AI \& Adelstein SJ 2005 Radiobiologic principles in radionuclide therapy. Journal of Nuclear Medicine $\mathbf{4 6}$ (Suppl 1) 4S-12S. 
Konijnenberg MW 2003 Is the renal dosimetry for $\left[{ }^{90} \mathrm{Y}\right.$-DOTA $\left.{ }^{0}, \mathrm{Tyr}^{3}\right]$ octreotide accurate enough to predict thresholds for individual patients? Cancer Biotherapy and Radiopharmaceuticals 18 619-625.

Krenning EP, de Jong M, Kooij PP, Breeman WA, Bakker WH, de Herder WW, van Eijck CH, Kwekkeboom DJ, Jamar F, Pauwels S \& Valkema R 1999a Radiolabelled somatostatin analogue(s) for peptide receptor scintigraphy and radionuclide therapy. Annals of Oncology 10 (Suppl 2) S23-S29.

Krenning EP, Valkema R, Kooij PP, Breeman WA, Bakker WH, de Herder WW, van Eijck CH, Kwekkeboom DJ, de Jong M \& Pauwels S 1999b Scintigraphy and radionuclide therapy with [indium-111-labelled-diethyl triamine penta-acetic acid-D-Phe1]-octreotide. Italian Journal of Gastroenterology and Hepatology 31 (Suppl 2) S219-S223.

Krenning EP, Kwekkeboom DJ, Valkema R, Pauwels S, Kvols LK \& de Jong M 2004 Peptide receptor radionuclide therapy. Annals of the New York Academy of Sciences 1014 234-245.

Krenning EP, Valkema R, Kwekkeboom DJ, de Herder WW, van Eijck CH, de Jong M, Pauwels S \& Reubi JC 2005 Molecular imaging as in vivo molecular pathology for gastroenteropancreatic neuroendocrine tumors: implications for follow-up after therapy. Journal of Nuclear Medicine 46 (Suppl 1) 76S-82S.

Kwekkeboom DJ, Bakker WH, Kam BL, Teunissen JJ, Kooij PP, de Herder WW, Feelders RA, van Eijck CH, de Jong M, Srinivasan A, Erion JL \& Krenning EP 2003 Treatment of patients with gastro-entero-pancreatic (GEP) tumours with the novel radiolabelled somatostatin analogue $\left[{ }^{177} \mathrm{Lu}-\mathrm{DOTA}(0), \mathrm{Tyr}^{3}\right]$ octreotate. European Journal of Nuclear Medicine and Molecular Imaging 30 417-422.

Kwekkeboom DJ, Mueller-Brand J, Paganelli G, Anthony LB, Pauwels S, Kvols LK, O’Dorisio TM, Valkema R, Bodei L, Chinol M, Maecke HR \& Krenning EP 2005 Overview of results of peptide receptor radionuclide therapy with 3 radiolabeled somatostatin analogs. Journal of Nuclear Medicine 46 (Suppl 1) 62S-66S.

Larson SM \& Krenning EP 2005 A pragmatic perspective on molecular targeted radionuclide therapy. Journal of Nuclear Medicine 46 (Suppl 1) 1S-3S.

Leimer M, Kurtaran A, Smith-Jones P, Raderer M, Havlik E, Angelberger P, Vorbeck F, Niederle B, Herold C \& Virgolini I 1998 Response to treatment with yttrium 90-DOTA-lanreotide of a patient with metastatic gastrinoma. Journal of Nuclear Medicine 39 2090-2094.

Lewington VJ 2003 Targeted radionuclide therapy for neuroendocrine tumours. Endocrine-Related Cancer 10 497-501.

Mukherjee JJ, Kaltsas GA, Islam N, Plowman PN, Foley R, Hikmat J, Britton KE, Jenkins PJ, Chew SL, Monson JP, Besser GM \& Grossman AB 2001 Treatment of metastatic carcinoid tumours, phaeochromocytoma, paraganglioma and medullary carcinoma of the thyroid with (131)I-meta-iodobenzylguanidine [(131)I-mIBG]. Clinical Endocrinology 55 47-60.

Oberg K 2002 Carcinoid tumors: molecular genetics, tumor biology, and update of diagnosis and treatment. Current Opinion in Oncology 14 38-45.

Oberg K 2004a Future aspects of somatostatin-receptormediated therapy. Neuroendocrinology 80 (Suppl 1) 57-61.

Oberg K 2004b Management of neuroendocrine tumours. Annals of Oncology 15 (Suppl 4) iv293-iv298.

Oberg K, Astrup L, Eriksson B, Falkmer SE, Falkmer UG, Gustafsen J, Haglund C, Knigge U, Vatn MH \& Valimaki M 2004 Guidelines for the management of gastroenteropancreatic neuroendocrine tumours (including bronchopulmonary and thymic neoplasms).

I. General overview. Acta Oncology 43 617-625.

O’Donoghue JA, Bardies M \& Wheldon TE 1995

Relationships between tumor size and curability for uniformly targeted therapy with beta-emitting radionuclides. Journal of Nuclear Medicine 36 1902-1909.

Otte A, Cybulla M \& Weiner SM $2002{ }^{90}$ Y-DOTATOC and nephrotoxicity. European Journal of Nuclear Medicine and Molecular Imaging 291543.

Paganelli G, Bodei L, Handkiewicz JD, Rocca P, Papi S, Lopera SM, Gatti M, Chinol M, Bartolomei M, Fiorenza M \& Grana C $2002{ }^{90}$ Y-DOTA-D-Phe1-Try ${ }^{3}$-octreotide in therapy of neuroendocrine malignancies. Biopolymers 66 393-398.

Pauwels S, Barone R, Walrand S, Borson-Chazot F, Valkema R, Kvols LK, Krenning EP \& Jamar F 2005 Practical dosimetry of peptide receptor radionuclide therapy with (90)Y-labeled somatostatin analogs. Journal of Nuclear Medicine 46 (Suppl 1) 92S-98S.

Reubi JC 2004 Somatostatin and other peptide receptors as tools for tumor diagnosis and treatment. Neuroendocrinology 80 (Suppl 1) 51-56.

Reubi JC \& Waser B 2003 Concomitant expression of several peptide receptors in neuroendocrine tumours: molecular basis for in vivo multireceptor tumour targeting. European Journal of Nuclear Medicine and Molecular Imaging 30 781-793.

Reubi JC, Schar JC, Waser B, Wenger S, Heppeler A, Schmitt JS \& Macke HR 2000 Affinity profiles for human somatostatin receptor subtypes $\mathrm{SST}_{1}-\mathrm{SST}_{5}$ of somatostatin radiotracers selected for scintigraphic and radiotherapeutic use. European Journal of Nuclear Medicine 27 273-282.

Reubi JC, Korner M, Waser B, Mazzucchelli L \& Guillou L 2004 High expression of peptide receptors as a novel target in gastrointestinal stromal tumours. European Journal of Nuclear Medicine and Molecular Imaging 31 803-810.

Reubi JC, Macke HR \& Krenning EP 2005 Candidates for peptide receptor radiotherapy today and in the future. Journal of Nuclear Medicine $\mathbf{4 6}$ (Suppl 1) $67 \mathrm{~S}-75 \mathrm{~S}$.

Robbins RJ \& Schlumberger MJ 2005 The evolving role of (131)I for the treatment of differentiated 
thyroid carcinoma. Journal of Nuclear Medicine $\mathbf{4 6}$ (Suppl 1) 28S-37S.

Sgouros G 2005 Dosimetry of internal emitters. Journal of Nuclear Medicine 46 (Suppl 1) 18S-27S.

Siegel JA \& Stabin MG 1994 Absorbed fractions for electrons and beta particles in spheres of various sizes. Journal of Nuclear Medicine 35 152-156.

Solcia E, Rindi G, Paolotti D, La Rosa S, Capella C \& Fiocca R 1999 Clinicopathological profile as a basis for classification of the endocrine tumours of the gastroenteropancreatic tract. Annals of Oncology $\mathbf{1 0}$ (Suppl 2) S9-S15.

Teunissen JJ, Kwekkeboom DJ \& Krenning EP 2004 Quality of life in patients with gastroenteropancreatic tumors treated with $\left[{ }^{177}\right.$ Lu-DOTA ${ }^{0}$, Tyr $\left.^{3}\right]$ octreotate. Journal of Clinical Oncology 22 2724-2729.

Valkema R, de Jong M, Bakker WH, Breeman WA, Kooij PP, Lugtenburg PJ, de Jong FH, Christiansen A, Kam BL, De Herder WW, Stridsberg M, Lindemans J, Ensing G \& Krenning EP 2002 Phase I study of peptide receptor radionuclide therapy with [In-DTPA] octreotide: the Rotterdam experience. Seminars in Nuclear Medicine 32 110-122.

Valkema R, Pauwels SA, Kvols LK, Kwekkeboom DJ, Jamar F, de Jong M, Barone R, Walrand S, Kooij PP, Bakker WH, Lasher J \& Krenning EP 2005 Long-term follow-up of renal function after peptide receptor radiation therapy with (90)Y-DOTA(0), Tyr(3)-octreotide and (177)Lu-DOTA(0), Tyr(3)-octreotate. Journal of Nuclear Medicine 46 (Suppl 1) 83S-91S. van Hagen PM, Breeman WA, Bernard HF, Schaar M, Mooij CM, Srinivasan A, Schmidt MA, Krenning EP \& de Jong M 2000 Evaluation of a radiolabelled cyclic DTPA-RGD analogue for tumour imaging and radionuclide therapy. Internatinal Journal of Cancer $\mathbf{9 0}$ 186-198.

Virgolini I, Britton K, Buscombe J, Moncayo R, Paganelli G \& Riva P 2002a In- and Y-DOTA-lanreotide: results and implications of the MAURITIUS trial. Seminars in Nuclear Medicine 32 148-155.

Virgolini I, Traub T, Novotny C, Leimer M, Fuger B, Li SR, Patri P, Pangerl T, Angelberger P, Raderer M, Burggasser G, Andreae F, Kurtaran A \& Dudczak R $2002 b$ Experience with indium-111 and yttrium-90-labeled somatostatin analogs. Current Pharmacy Design 8 1781-1807.

Waldherr C, Pless M, Maecke HR, Haldemann A \& MuellerBrand J 2001 The clinical value of $\left[{ }^{90}\right.$ Y-DOTA]-D-Phe1Tyr ${ }^{3}$-octreotide $\left({ }^{90} \mathrm{Y}\right.$-DOTATOC) in the treatment of neuroendocrine tumours: a clinical phase II study. Annals of Oncology 12 941-945.

Waldherr C, Pless M, Maecke HR, Schumacher T, Crazzolara A, Nitzsche EU, Haldemann A \& MuellerBrand J 2002 Tumor response and clinical benefit in neuroendocrine tumors after 7.4 GBq (90)Y-DOTATOC. Journal of Nuclear Medicine 43 610-616.

Wiseman GA \& Kvols LK 1995 Therapy of neuroendocrine tumors with radiolabeled MIBG and somatostatin analogues. Seminars in Nuclear Medicine A 25 272-278. 
